ISSN 1996-1944

www.mdpi.com/journal/materials

Review

\title{
Recent Progress in Ferrocene-Modified Thin Films and Nanoparticles for Biosensors
}

\section{Shigehiro Takahashi and Jun-ichi Anzai *}

Graduate School of Pharmaceutical Sciences, Tohoku University, Aramaki, Aoba-ku, Sendai 980-8578, Japan; E-Mail: t-shigehiro@m.tohoku.ac.jp

* Author to whom correspondence should be addressed; E-Mail: junanzai@ mail.pharm.tohoku.ac.jp; Tel.: +81-22-795-6841; Fax: +81-22-795-6840.

Received: 30 October 2013; in revised form: 2 December 2013 / Accepted: 2 December 2013 / Published: 6 December 2013

\begin{abstract}
This article reviews recent progress in the development of ferrocene (Fc)-modified thin films and nanoparticles in relation to their biosensor applications. Redox-active materials in enzyme biosensors commonly use Fc derivatives, which mediate electron transfer between the electrode and enzyme active site. Either voltammetric or amperometric signals originating from redox reactions of $\mathrm{Fc}$ are detected or modulated by the binding of analytes on the electrode. Fc-modified thin films have been prepared by a variety of protocols, including in situ polymerization, layer-by-layer (LbL) deposition, host-guest complexation and molecular recognitions. In situ polymerization provides a facile way to form Fc thin films, because the Fc polymers are directly deposited onto the electrode surface. LbL deposition, which can modulate the film thickness and Fc content, is suitable for preparing well-organized thin films. Other techniques, such as host-guest complexation and protein-based molecular recognition, are useful for preparing Fc thin films. Fc-modified Au nanoparticles have been widely used as redox-active materials to fabricate electrochemical biosensors. Fc derivatives are often attached to Au nanoparticles through a thiol-Au linkage. Nanoparticles consisting of inorganic porous materials, such as zeolites and iron oxide, and nanoparticle-based composite materials have also been used to prepare Fc-modified nanoparticles. To construct biosensors, Fc-modified nanoparticles are immobilized on the electrode surface together with enzymes.
\end{abstract}

Keywords: ferrocene; biosensor; electron-transfer mediator; thin film; electro-polymerization; layer-by-layer deposition; Au nanoparticle 


\section{Introduction}

Redox-active materials, including small ions, molecules and polymers, are common electron-transfer mediators and electrochemical tags in biosensors. A wide range of materials are available for electron transfer, including iron and osmium complexes, hydroquinones, anthraquinones and organic dyes, such as methylene blue [1-6]. The corresponding polymers of such materials are also useful for mediator immobilization on an electrode surface. Among these materials, ferrocene $(\mathrm{Fc})$ and $\mathrm{Fc}$ polymers are most commonly used in biosensor fabrication because of their high stability in redox reactions and facile derivative syntheses. Fc is a stable metal complex consisting of an iron(II) atom sandwiched between two cyclopentadienyl ligands. A typical example of Fc-mediated biosensors is an amperometric glucose sensor. Amperometric glucose sensors are constructed by immobilizing glucose oxidase $(\mathrm{GOx})$ on the surface of metal or carbon electrodes, where the redox reaction of Fc is coupled with GOx -catalyzed glucose oxidation to mediate electron transfer between the active center of GOx and the electrode (Figure 1) [7,8]. Fc derivatives are usually confined on the electrode surface to construct reagentless biosensors, although dissolved Fc derivatives can also mediate electron transfer.

Figure 1. Ferrocene $(\mathrm{Fc})$-mediated electron transfer in amperometric glucose sensors. Reprinted with permission from Anzai et al. [8]. Copyright 2001 Pharmaceutical Society of Japan.

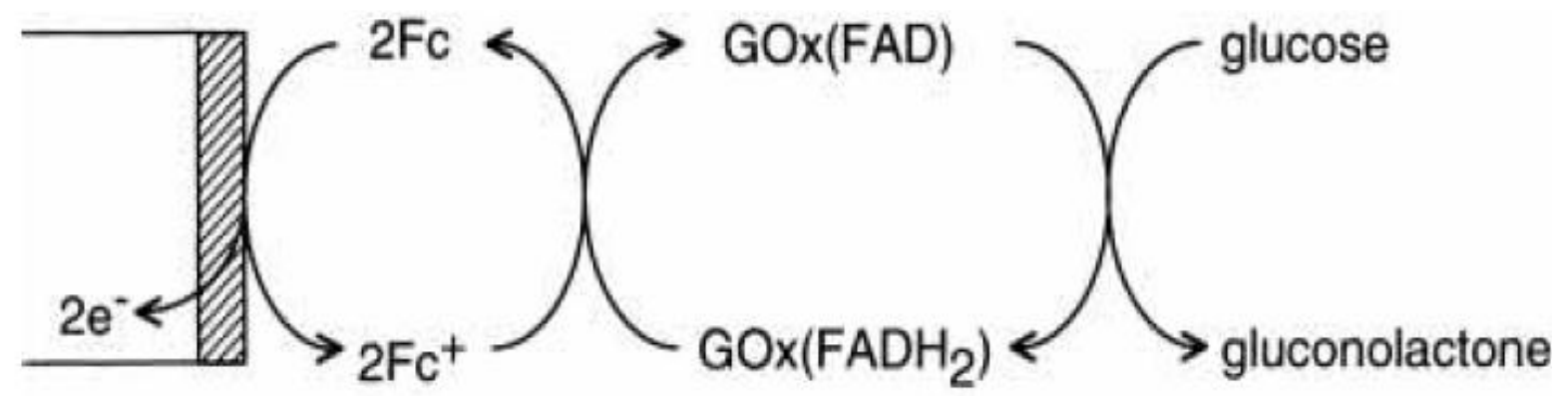

\section{Electrode}

\section{Fc: Ferrocene derivative}

In other examples, Fc derivatives serve as redox-active tags for electrochemical determination of analytes. Typically, DNA-based sensors are constructed by modifying the electrode surface with single-stranded DNA chains with an Fc tag [9]. Redox reaction of the Fc tag depends on DNA chain hybridization, thus yielding a hybridization-dependent redox signal (Figure 2). An Fc-tagged aptamer has also been attached to the electrode surface [10]. In the examples described above, the design and fabrication of the Fc surface layer on the electrode is crucial for modulating the sensor response characteristics. Consequently, many protocols have been developed for constructing Fc-modified surface layers on biosensor electrodes. In this context, much research has recently focused on developing highly ordered thin films and nanoparticles. In this review, we focus on recent progress in the development of Fc-modified thin films and nanoparticles for biosensor applications. 
Figure 2. Fc-tagged DNA biosensor detecting hybridization. Reprinted with permission from White et al. [9]. Copyright 2009 American Chemical Society.
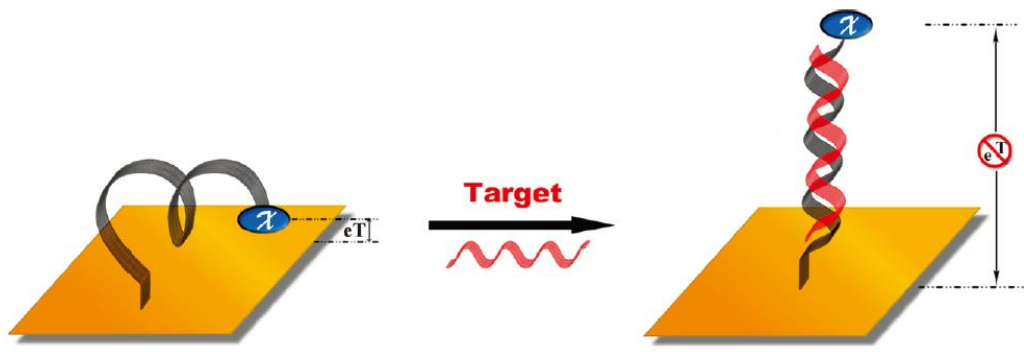

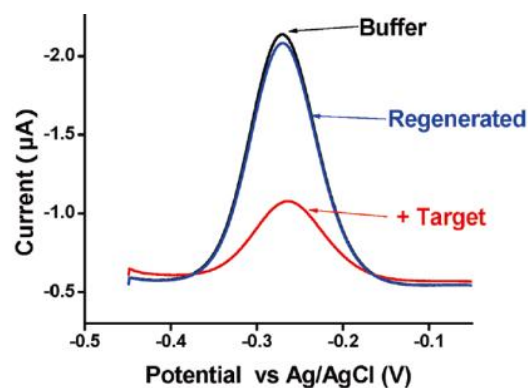

\section{Fc-Containing Thin Films}

Fc-modified polymers have been widely used to form thin films on electrode surfaces for fabricating mediator-type biosensors. Three different strategies are often employed in the preparation of Fc thin films: in situ polymerization, layer-by-layer (LbL) deposition and selective adsorption.

\subsection{In Situ Polymerized Fc Films}

In situ polymerization is a facile way to form thin films on electrode surfaces, because it circumvents difficulties in chemical synthesis and polymer purification. In situ synthesized polymers are usually deposited on the electrode surface during polymerization. Plasma polymerization $[11,12]$, photopolymerization [13,14], chemical polymerization [15] and electropolymerization [16-27] have all been used in this context. Muguruma and Uehara reported excellent plasma-polymerized film properties, including good substrate adhesion, a flat pinhole-free surface and high mechanical and chemical stability [11,12]. They used plasma polymerization to prepare thin films of dimethylaminomethylferrocene on the surface of a GOx -modified electrode. A highly effective electron-mediation system was constructed in the glucose sensors. An advantage of plasma polymerization is that the entire process is carried out in the vapor phase. Therefore, plasma-polymerized films are suitable for high-throughput production of microscale bioelectronic devices. Heng and coworkers reported a single-step glucose sensor fabrication protocol based on photochemically polymerized films consisting of Fc derivatives and GOx [13,14]. A mixed solution of 2-hydroxyethyl methacrylate, Fc derivative, initiator and GOx was deposited on the surface of a screen-printed carbon electrode and irradiated with UV light. Unsubstituted Fc is physically trapped in the film, whereas vinylferrocene is covalently immobilized. The main advantage of this procedure is that biosensors can be constructed in a single step without any pre- or post-treatment with enzymes. A conventional polymerization procedure is also useful for modifying an electrode surface with Fc thin films [15].

Electropolymerized conductive polymers have attracted considerable attention in the development of electrochemical sensors and reactors [16-23]. Conductive polymer films can be deposited on electrode surfaces by using heterocyclic compounds, such as pyrroles [16-19], thiophenes [20,23] and anilines [23] as monomers. An advantage of electrochemical polymerization procedures is that regulating the applied electrode potential and/or electric current readily controls film formation. Film thickness can be controlled by changing the electrolysis time. Moreover, functional biomolecules, such as proteins and nucleic acids, can be entrapped in electropolymerized films if the biomolecules are 
dissolved in the monomer solution during electropolymerization [16,21]. Considerable flexibility in monomer types enables the modulation of the films' electrochemical properties. A variety of monomeric structures, including Fc derivatives, have been synthesized for improving the conductivity and electron-transfer efficiency of the films. Fc-substituted thiophene and terthiophene have been used as monomers for preparing conducting polymers on a Pt electrode [24]. The polymer-modified $\mathrm{Pt}$ electrode facilitates electron transfer to cytochrome $\mathrm{C}$, suggesting the potential use of the electrode in biosensors. Fang and coworkers used Fc-substituted cationic polythiophene, which was prepared via chemical polymerization, as a redox marker for detecting DNA hybridization on the surface of peptide nucleic acid (PNA)-modified electrodes [25]. Fc-substituted polythiophene is electrostatically bound to only the PNA-DNA hybridization product, yielding an electrochemical signal in the presence of target DNA chains, whereas no signal is observed for four-base mismatch DNA. Leclerc and coworkers used aggregates consisting of Fc-substituted polythiophene as a redox marker for ultrasensitive determination of target DNA chains (the detection limit of the target DNA was $4 \times 10^{-16} \mathrm{M}$ ) [26]. The utility of polymeric redox markers in sensitive DNA detection has been reported [27]. Şenel recently proposed reagentless glucose biosensors based on Fc-substituted polypyrrole films [28]. The author modified the films with GOx and electrochemically deposited them on the electrode surface. The Fc moieties in the films served as electron-transfer mediators between GOx and the electrode.

\subsection{LbL-Deposited Fc Films}

The LbL deposition technique, commonly used for constructing thin films and nanoscale assemblies [29-35], is a facile way to form polymer thin films by alternating, repeated adsorption of cationic and anionic polymers onto the substrate from aqueous solution. Such thin films are common in thin-film devices because of the wide array of useful polymer types, including biopolymers, such as proteins [36,37], polysaccharides [38,39] and polypeptides [40]. LbL film-modified devices are used in biosensors [41], ion-selective membranes [42], stimuli-sensitive systems [43] and drug delivery [44]. Early research demonstrated that Fc-containing LbL films are useful for fabricating mediator-type biosensors and electrocatalysts [45-51]. For example, Calvo and coworkers prepared glucose biosensors by using an Au electrode coated with $\mathrm{LbL}$ films consisting of Fc-bearing poly(allylamine) (Fc-PAH) and GOx [45]. The Fc moieties in the LbL film effectively mediated electron transfer between GOx and the electrode, depending on the film thickness and configuration. Sun and coworkers improved Fc-PAH/GOx LbL film-modified glucose sensors by using periodate-oxidized GOx to covalently connect the LbL layers through Schiff-base formation [46]. Copolymers consisting of vinylferrocene and (methacryloyloxy)ethyl trimethylammonium units have also been used to construct LbL films [47]. Our laboratory has prepared Fc-containing LbL film-coated electrodes [48-50]. The redox properties of the Fc LbL film-coated electrodes are dependent on the polymer type, Fc content in the polymer and LbL film configuration. We used our Fc-PAH film-coated electrodes for solution-phase electrocatalytic determination of ascorbic acid. Fc-polymer films containing DNA may also be useful for sensing intercalating drugs [51]. An advantage of LbL films arises from facile regulation of the thickness and multilayer structure of the film, facilitating the film-structure design at the molecular level and, thus, performance optimization. 
Zheng and Suye's group developed enzyme and DNA biosensors using Fc polymers [52-55]. They incorporated L-proline dehydrogenase and Fc-PAH into the LbL film through electrostatic affinity to construct L-proline sensors [54]. The catalytic current of the sensor in response to L-proline increased as the number of Fc-PAH layers in the LbL film was increased. For preparing L-lysine sensors, Zheng and Suye's group synthesized a poly(ethylenimine) (PEI) derivative bearing coenzyme (nicotinamide adenine dinucleotide, NAD) and Fc moieties. They alternately deposited the Fc-NAD-bearing PEI and L-lysine dehydrogenase on an Au electrode to prepare reagentless L-lysine sensors, in which all the components (enzyme, coenzyme and electron-transfer mediator) were confined in the LbL film (Figure 3) [55]. The L-lysine sensor exhibits an electrochemical response to L-lysine in the concentration range of 1-120 mM. Fc-PAH and Fc-PEI are often used as the cationic component in preparing electrostatic LbL films. In this way, negatively charged enzymes are successfully combined with the Fc polymers to form LbL films for biosensors. Similarly, Fc-PEI has been used to fabricate $\mathrm{Au}$ nanoparticle (AuNP)/Fc-PEI LbL films [56,57]. UV-Vis absorption spectroscopy and atomic force microscopy clearly show a layered structure in the AuNP/Fc-PEI films [56]. The AuNP/Fc-PEI film-coated electrodes exhibit electrocatalytic reactions (ascorbic acid oxidation and oxygen reduction). Dong and Wang's group used AuNP/Fc-PEI film-coated electrodes to construct aptamer sensors for cocaine [57]. They modified AuNPs on the surface of a (AuNP/Fc-PEI $)_{2}$ film-coated electrode via a cocaine-sensitive aptamer fragment. The redox current originating from the Fc moieties in the LbL film decreases in the presence of aptamer and cocaine (i.e., in accordance with cocaine concentration) in the range of $0.1-88.8 \mu \mathrm{M}$. They attribute the reduced redox current to the reduced apparent diffusion coefficient of the Fc moiety in the film. This strategy has wide applicability in fabricating reagentless affinity sensors, although the response mechanism of the sensors must be further studied. This system is applicable to thrombin and lysozyme determination $[57,58]$.

Figure 3. A reagentless L-lysine sensor prepared using Fc-(nicotinamide adenine dinucleotide)-bearing poly(ethylenimine). Reprinted with permission from Zhang et al. [55]. Copyright 2008 Wiley-VCH. NAD, nicotinamide adenine dinucleotide; PEI, poly(ethylenimine).
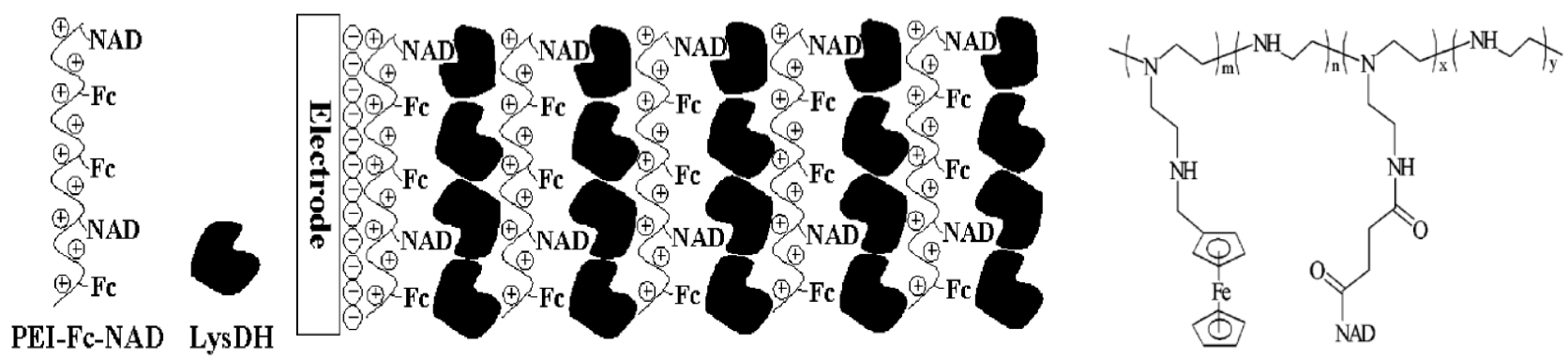

Different types of Fc polymers have been used as components of redox-active LbL films. Ishihara and coworkers used phosphorylcholine polymers containing an $\mathrm{Fc}$ unit to prepare a multilayered hydrogel on an electrode surface to fabricate glucose sensors (Figure 4) [59]. Vancso and coworkers prepared water-soluble ferrocenylsilane polymers that have positive or negative charges [60,61]. These Fc polymers contain Fc moieties in their main chains, as opposed to pendant Fc moieties in Fc-PAH and Fc-PEI. They incorporated ferrocenylsilane polymers into LbL films and microcapsules, the 
thickness, swelling and permeability of which are tunable through redox reactions of the Fc residues [62-64]. Their Fc polymer-modified electrode is useful for electrocatalytic determination of ascorbic acid [65].

Figure 4. A glucose sensor prepared using phosphorylcholine polymers containing an Fc unit. Reprinted with permission from Ishihara et al. [59]. Copyright 2012 Elsevier. LbL, layer-by-layer.

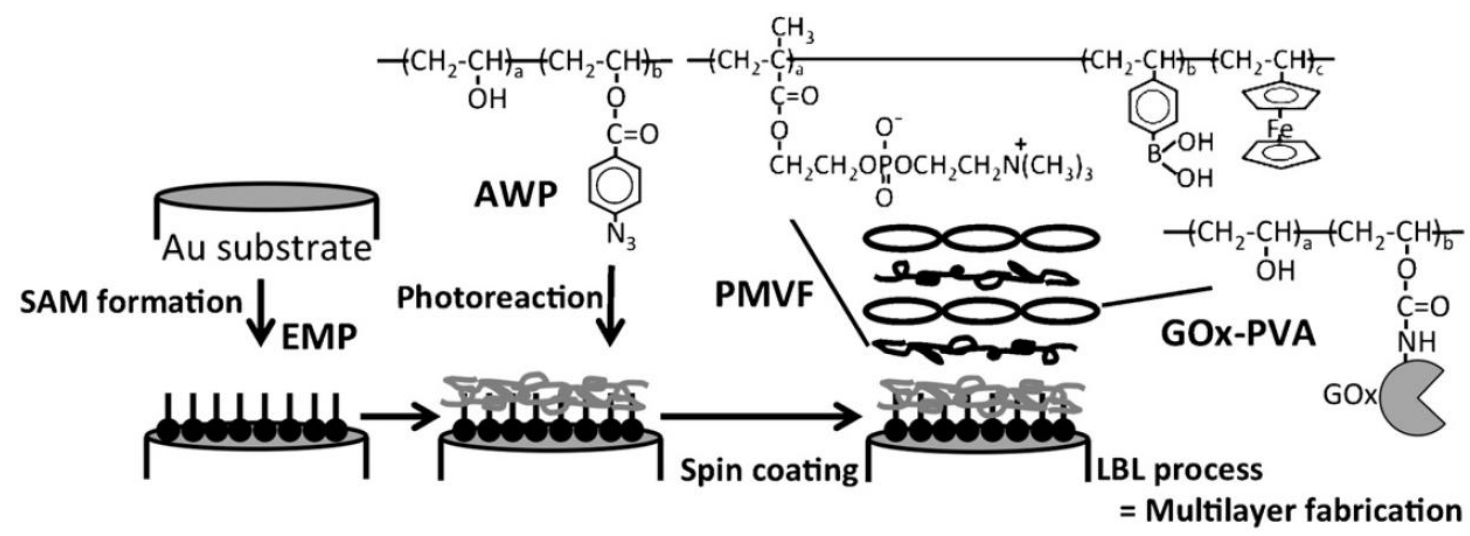

\subsection{Host-Guest Complexation and Molecular Recognition}

$\mathrm{Fc}$ and Fc polymers can be immobilized on the surface of electrodes through host-guest complexation. Cyclodextrins (CDs) are cyclic oligosaccharides that form inclusion complexes with hydrophobic molecules. CDs are commonly used for forming thin films and chemically modifying electrode surfaces [66-69]. Marken and coworkers deposited carboxymethyl- $\gamma-C D$ and mesoporous $\mathrm{TiO}_{2}$ nanoparticles onto the surface of an indium tin oxide (ITO) electrode to form thin layers [70]. The 1,1'-ferrocenedimethanol (DMFc) complex with carboxymethyl- $\gamma$-CD exhibits characteristic redox signals on the ITO surface. However, the DMFc is released from the electrode surface upon oxidation because of weak binding of oxidized DMFc to the CD. On the other hand, the Fc polymer is firmly immobilized on the surface of the CD monolayer-modified electrode. O'Sullivan and coworkers fabricated genosensors based on host-guest complexation on a CD monolayer-modified electrode (Figure 5) [68]. The multipoint binding between the DNA-modified carboxymethylcellulose (CMC) and $\mathrm{CD}$ enables stable anchoring of the CMC derivative on the surface, despite the fact that the 1:1 binding to $\mathrm{CD}$ is relatively weak. In another report, the same group synthesized CMC derivatives, dually modified with Fc and DNA chains, to fabricate DNA sensors [71]. They immobilized the Fc-DNA-modified CMC on the surface of a CD monolayer-modified electrode through host-guest complexation. Thus, the Fc moiety served as redox-active sites, as well as anchoring sites on the electrode surface. In this context, Fc polymers were incorporated into thin films and microcapsules through CD complexation [72,73]. These Fc-containing materials are expected to be useful for fabricating electrochemical biosensors.

Binding proteins, such as avidin and lectin, are also useful tools for immobilizing functional molecules on solid surfaces [33,74-78]. Tiefenauer and coworkers prepared Fc-labeled avidin for assembling protein architectures, to which they coupled biotinylated enzymes to fabricate biosensors $[79,80]$. They used avidin as a linker for immobilizing biotinylated alkaline phosphatase on the surface of 
biotin-terminated Fc monolayer films [81]. They studied the voltammetric properties of Fc-sugar and Fc-glycogen conjugates in the presence and absence of lectin [82-85]. The Fc conjugates will be used to construct sugar sensors. Fc-labeled aptamers are also useful for fabricating electrochemical biosensors $[86,87]$.

Figure 5. Genosensor fabrication based on host-guest complexation on an electrode surface. Reprinted with permission from O’Sullivan et al. [68]. Copyright 2011 Elsevier.

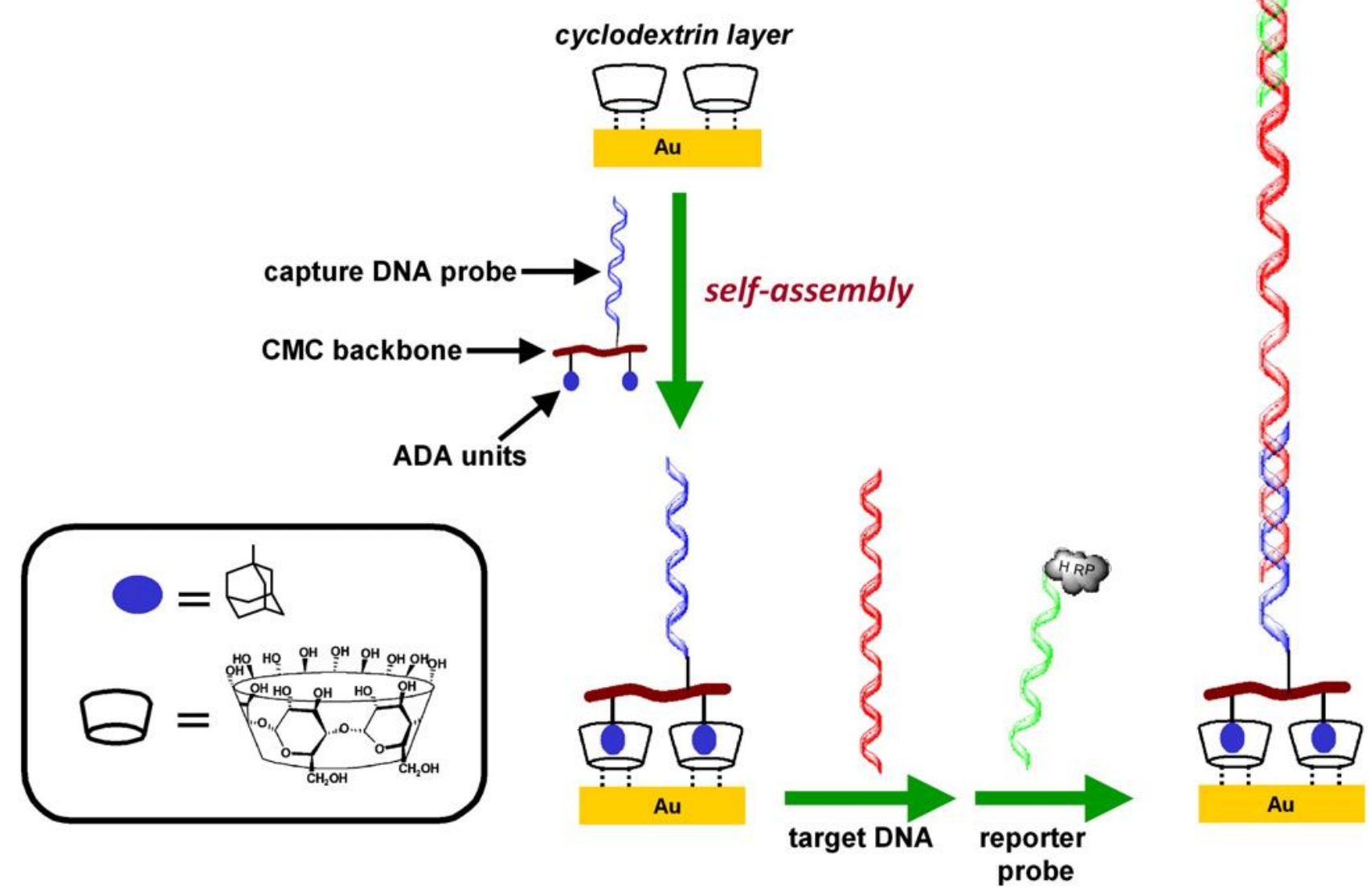

\subsection{Miscellaneous}

Interesting procedures for immobilizing Fc on electrode surfaces, based on click chemistry [88,89] and boronate ester formation [90], have recently been reported. A Au electrode was modified with an azide-terminated self-assembled monolayer, to which alkyne-substituted Fc was added via a click reaction in the presence of $\mathrm{Cu}^{2+}$ catalyst [88]. The corresponding Fc-modified electrode exhibited a strong response to ascorbic acid in the range of $5.0 \times 10^{-12}$ to $1.0 \times 10^{-9} \mathrm{M}$. Alternatively, azide-substituted Fc can be confined to an alkyne-modified surface [89]. Fc-boronic acid was immobilized on an electrode surface via boronate ester formation, in which a tyrosine-modified electrode was treated with tyrosinase in advance to generate catechol functionality on the surface [90]. Thus, the extent of Fc-boronic acid immobilization or the magnitude of the redox signal depends on the catalytic activity of tyrosinase, enabling tyrosinase determination. Other papers report the use of 
Fc-boronic acid as a redox marker in the voltammetric determination of sugars, phenols and glycated hemoglobin [91-95].

Fc-PEI is commonly used to prepare amperometric biosensors because of its desirable properties, such as high segmental mobility of the polymer chain, facile control of Fc substitution degree and high swellability in water [96]. Glatzhofer and Schmidtke's group developed high-performance glucose and $\mathrm{H}_{2} \mathrm{O}_{2}$ sensors using Fc-modified linear PEI [97]. Their linear Fc-PEI-based sensors enable glucose detection in the micromolar range. They evaluated the effects of Fc methylation in the Fc-PEI complex [98]. Dimethyl- and tetramethyl-substituted Fc polymers were identified as promising redox components for biofuel cells and biosensors. Furthermore, Fc-modified polysiloxane has been used to construct glucose biosensors [99]. The redox potential of the Fc moiety in the polymer shifts in the negative region as a result of composite formation with chitosan. The composite is a useful scaffold for enzyme immobilization. Fc-tethered poly(amidoamine) dendrimers (Fc-D) have been employed for constructing a biosensor interface on electrodes [100]. Fc-D can be immobilized on the surface of a carboxyl-terminated monolayer-modified Au electrode through an amide linkage, on which periodate-oxidized GOx is assembled through Schiff-base formation. Electron-transfer mediation through the Fc-D layer depends on the linker length between the Fc residues and the dendrimer. Reviews on recent progress in biomedical and biosensor applications of dendrimers are available [101,102].

Fc thin films sometimes suffer from instability in the redox reaction. Cross-linked Fc-PEI films are unstable upon repeated cyclic voltammetry scanning in phosphate solutions at $\mathrm{pH}$ 7.0, whereas the film is stable at $\mathrm{pH} 5.0$ [103]. The peak current in cyclic voltammetry decreases with increasing scan

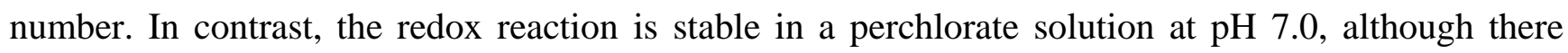
is instability at $\mathrm{pH} 11$. This is attributable to the instability of ferrocenium (oxidized Fc), which decomposes in the presence of nucleophiles. The instability of Fc-modified films has been studied in relation to the chemical structure of the polymer backbone. Bunte and Rühe synthesized two different types of poly(acrylic acid) derivatives bearing Fc side chains [104]. The Fc polymer is unstable at $\mathrm{pH} 7.2$ if the polymer contains secondary amino groups in the side chains connecting $\mathrm{Fc}$ to the polymer backbone, whereas there is a stable redox reaction for an Fc polymer with poly(ethylene oxide) side chains. These results suggest that the instability of $\mathrm{Fc}$ thin films arises from nucleophilic anion uptake in the film through amino-group binding.

\section{Fc-Modified Nanoparticles}

Nanoparticles consisting of metals [105-108], metal oxides [107,109], metal complexes [110] and polymers [111] are generating much interest, because of their attractive optical and electronic properties, as well as their potential applications in a wide variety of fields, such as biosensor development. In the following sections, we discuss Fc-containing nanoparticles employed in biosensor assemblies, in which Fc derivatives are attached to the nanoparticles to improve the electron-transfer properties of Fc. 


\subsection{Fc-Modified Au Nanoparticles}

AuNPs are commonly used as the core material to immobilize Fc derivatives, owing to the ease of surface modification with thiol compounds. Self-assembled monolayer films based on the thiol-Au linkage are commonly used for modifying Au electrode surfaces in biosensor fabrication $[3,112,113]$. Zhou and coworkers prepared Fc-modified AuNP/streptavidin conjugates using 6-ferrocenylhexanethiol and used their conjugates for voltammetric detection of DNA hybridization and proteins [114-117]. They attached AuNP/streptavidin conjugates to the electrode surface through streptavidin-biotin linkages. The electrode response was strongly enhanced, because AuNP/streptavidin conjugates contain $127 \pm 18 \mathrm{Fc}$ residues per AuNP, and one or two AuNPs are attached to each streptavidin molecule. A tumor-suppressor protein, p53, can be detected at concentrations as low as $2.2 \times 10^{-12} \mathrm{M}$ (Figure 6) [117]. Liu and Xia's group used Fc-modified AuNP/streptavidin conjugates for voltammetric determination of dopamine [118]. AuNPs co-modified with DNA and Fc have been prepared by using thiolated DNA and 6-ferrocenylhexanethiol; these AuNPs are used as a redox marker in voltammetric evaluation of site-specific DNA cleavage [119]. In another protocol, an Fc/6-thio- $\beta$-cyclodextrin inclusion complex was attached to AuNPs to construct amperometric glucose sensors [120]. Fc-modified Au nanoparticles were built into LbL architectures by alternating deposition of AuNPs and poly(diallyldimethylammonium chloride) [121]. Glassy carbon electrodes modified with the LbL film exhibit a catalytic response to ascorbic acid in the concentration range of $8 \times 10^{-6}$ to $6 \times 10^{-3} \mathrm{M}$. Escorcia and Dhirani fabricated an LbL film-coated electrode based on direct deposition of AuNPs and a dithio-substituted Fc derivative [122]. Voltammetric studies on the LbL film-coated electrodes suggest a disordered and porous structure of the LbL layer. Yuan and coworkers used AuNPs modified with Fc-labeled antibodies to prepare electrochemical immunosensors [123]. In all the research we have presented in this section, Fc derivatives were affixed to AuNPs via thiol-Au interactions.

Figure 6. p53 protein sensors based on Fc-modified AuNP/streptavidin conjugates. (a) shows the most stable p53 binding mode on the sensor electrode; while (b) depicts two other possible binding configurations. Reprinted with permission from Zhou et al. [117]. Copyright 2011 American Chemical Society.

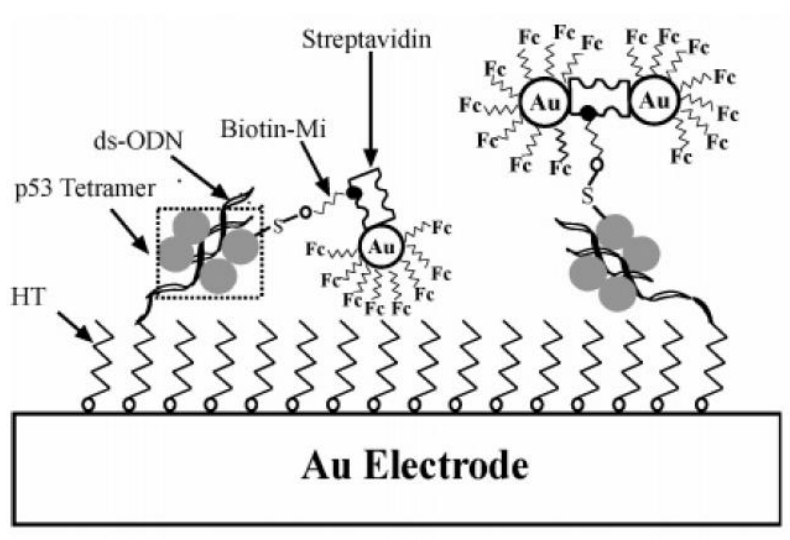

(a)

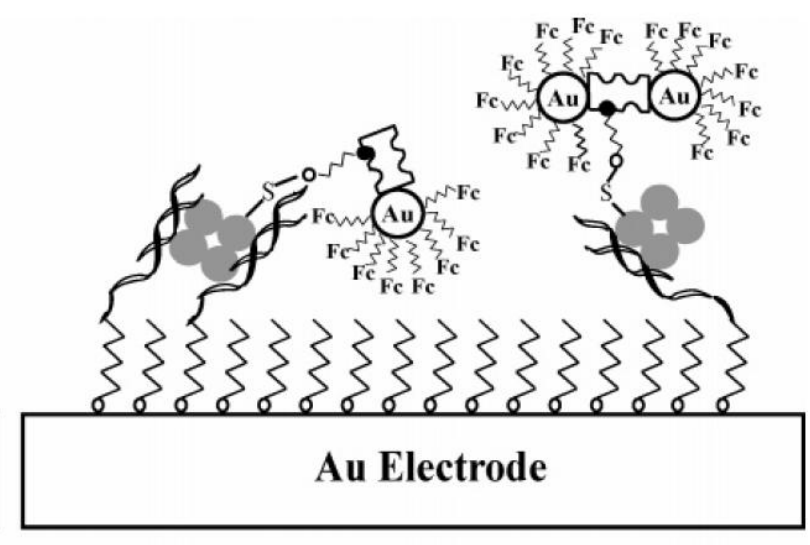

(b) 


\subsection{Fc-Modified Inorganic Porous Materials}

Inorganic porous materials, for example, $\mathrm{CaCO}_{3}$, zeolite, silica and iron oxide $\left(\mathrm{Fe}_{3} \mathrm{O}_{4}\right)$ particles, have been used as supports for immobilizing proteins in biosensor assemblies [124-127]. Their porous nature enables many proteins to bind to the surface. Li and Yang reported a facile protocol for preparing $\mathrm{Fc}$-modified $\mathrm{CaCO}_{3}$ particles [128], in which they dispersed $\mathrm{CaCO}_{3}$ particles, positively and negatively charged polymers and $\mathrm{Fc}$ in a methanol/water solution that they stirred at $60{ }^{\circ} \mathrm{C}$ until the solution evaporated. This simple procedure immobilizes the $\mathrm{Fc}$ and polymers on the surface of the $\mathrm{CaCO}_{3}$ particles. They further modified the $\mathrm{CaCO}_{3}$ particles with an antibody to fabricate immunosensors sensitive to interleukin-6. In another report, Fc was firmly encapsulated via sublimation in the cavities of a NaY zeolite through vapor diffusion [129]. The encapsulated $\mathrm{Fc}$ is electrochemically active and does not leak out of the cavity. The Fc-modified zeolite and GOx were immobilized on the electrode surface to fabricate glucose biosensors. Silica nanoparticles (approximately $15 \mathrm{~nm}$ in diameter) have been modified with Fc to fabricate glucose biosensors [130]. The surface of $\mathrm{Fe}_{3} \mathrm{O}_{4}$ particles is readily modified with $\mathrm{Fc}$ carboxylic acid via a dopamine bridge [131] and cyclodextrin complexation [132]. Dopamine is noteworthy as a stable modifier for $\mathrm{Fe}_{3} \mathrm{O}_{4}$ particles to further introduce functional molecules at the surface [133].

\subsection{Fc-Modified Composite Nanoparticles}

Composite nanoparticles are also useful as core materials for Fc complex assembly. Au-containing composites have been modified with Fc derivatives by taking advantages of thiol-Au binding. Luong and coworkers employed Au-carbon nanotube composites for immobilizing an Fc thiol derivative on an electrode surface [134,135]. The modified electrodes are useful for screening HIV-1 protease activity. A Au- $\mathrm{TiO}_{2}$ composite has been used to immobilize an $\mathrm{Fc}$ derivative for fabricating glucose biosensors [136].

Carbon nanotubes have widely been used as a conducting material in biosensor assemblies [137-141]. Pyrene-substituted Fc has been affixed to carbon nanotubes through $\pi-\pi$ stacking [142]. This strategy is valuable, because any type of pyrene-bearing compounds can be attached to carbon nanotubes through such stacking. A variety of protocols are available for preparing Fc-modified carbon nanotubes, which include bridging through amide [143] and Schiff-base bonding [144]. The surface of azide-bearing carbon nanotubes has been modified with alkyne-substituted Fc through click chemistry [145]. LbL deposition of negatively charged carbon nanotubes and either Fc-PAH or Fc-PEI yields biosensor platforms on electrode surfaces [146,147]. The surface of the LbL films was further modified with folic acid to recognize cancer cells specifically, enabling highly sensitive determination of human cervical carcinoma cells. There are potential uses for Fc-modified graphene and carbon nanoparticles in biosensor fabrication [148-150]. Fc-PEI nanobeads have been synthesized and mixed with GOx for drop-coating on a carbon electrode in order to develop amperometric glucose sensors (Figure 7) [151]. The Fc-PEI nanobeads were further modified with a conductive polymer, poly(3,4-ethylenedioxythiophene), to enhance the glucose sensor's performance. 
Figure 7. Redox polymer nanobeads composed of Fc-modified PEI for glucose biosensors. Reprinted with permission from Ho et al. [151]. Copyright 2010 American Chemical Society.

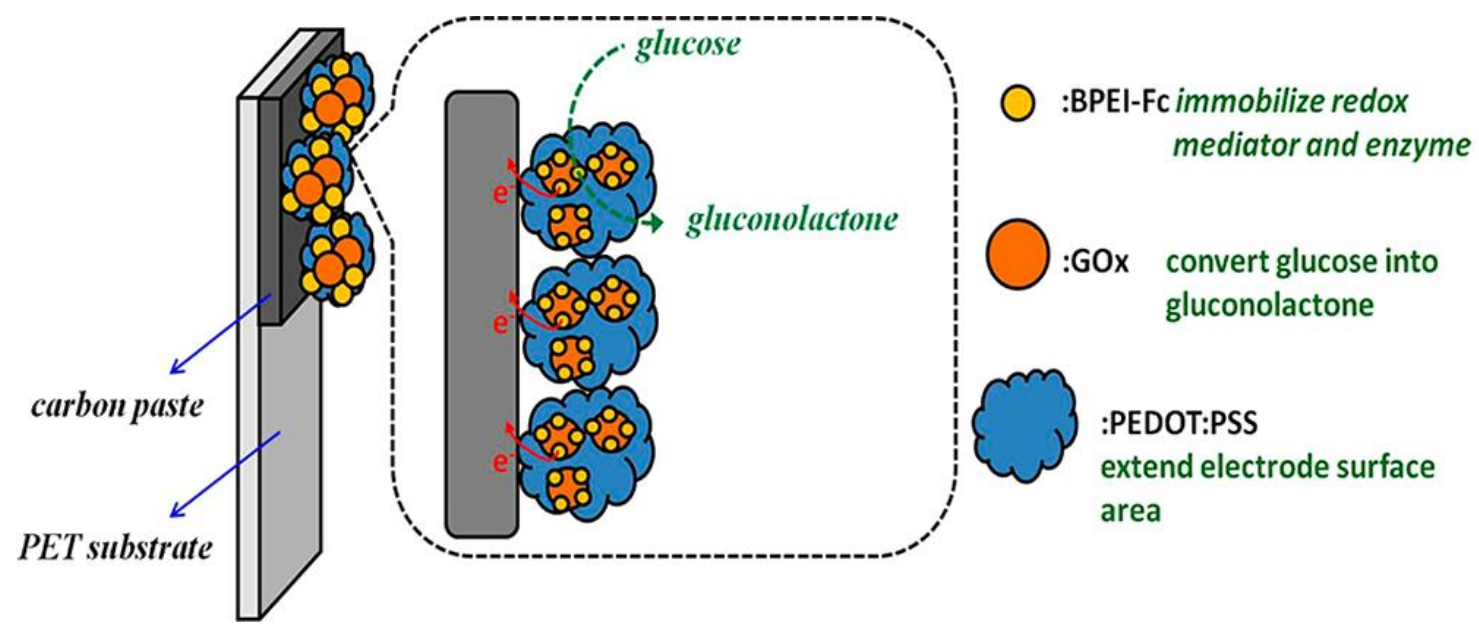

\section{Conclusions}

Fc derivatives can be successfully assembled into thin films and nanoparticles for the development of high-performance biosensors. Fc-modified thin films can be prepared on electrode surfaces by in situ polymerization, LbL deposition, host-guest complexation and molecular recognition. Nanoparticles consisting of metal oxides, metal complexes or polymers can be modified with Fc. Both Fc-modified thin films and nanoparticles exhibit excellent electron transfer and signal modulation in biosensors. The reasonable stability of $\mathrm{Fc}$ in redox reactions is advantageous in biosensor applications of Fc-modified thin films and nanoparticles, though, in some cases, improvement in the stability of Fc is further required. Consequently, Fc-modified thin films and nanoparticles are expected to find further applications in biosensors.

\section{Acknowledgments}

This work was supported in part by the Japan Society for the Promotion of Science Grants-in-Aid for Scientific Research (grant numbers 24659013 and 24790040).

\section{Conflicts of Interest}

The authors declare no conflict of interest.

\section{References}

1. Ricci, F.; Palleschi, G. Sensors and biosensors preparation, optimization and applications of Prussian Blue modified electrodes. Biosens. Bioelectron. 2005, 21, 389-407.

2. Sarma, A.K.; Vatsyayan, P.; Goswami, P.; Minteer, S.D. Recent advances in material science for developing enzyme electrodes. Biosens. Bioelectron. 2009, 24, 2313-2322.

3. Eckermann, A.L.; Feld, D.J.; Shaw, J.A.; Meade, T.J. Electrochemistry of redox-active self-assembled monolayers. Coord. Chem. Rev. 2010, 254, 1769-1802. 
4. Liu, A.; Wang, K.; Weng, A.; Lei, Y.; Lin, L.; Chen, W.; Lin, X.; Chen, Y. Development of electrochemical DNA biosensors. Trend Anal. Chem. 2012, 37, 101-111.

5. Moyo, M.; Okonkwo, J.O.; Agyei, N.M. Recent advances in polymeric materials used as electron mediators and immobilizing materials in developing enzyme electrodes. Sensors 2012, 12, 923-953.

6. Kotanen, C.N.; Moussy, F.G.; Carrara, S.; Guiseppi-Elie, A. Implantable enzyme amperometric biosensors. Biosens. Bioelectron. 2012, 35, 14-26.

7. Amer, W.A.; Wang, L.; Amin, A.M.; Ma, L.; Yu, H. Recent progress in the synthesis and applications of some ferrocene derivatives and ferrocene-based polymers. J. Inorg. Organomet. Polym. 2010, 20, 605-615.

8. Kobayashi, Y.; Hoshi, T.; Anzai, J. Glucose and lactate biosensors prepared by a layer-by-layer deposition of concanavalin A and mannose-labeled enzymes: Electrochemical response in the presence of electron mediators. Chem. Pharm. Bull. 2001, 49, 755-757.

9. Kang, D.; Zuo, X.; Yang, R.; Xia, F.; Plaxco, K.W.; White, R.J. Comparing the properties of electrochemical-based DNA sensors employing different redox tags. Anal. Chem. 2009, 81, 9109-9113.

10. Song, M.-J.; Lee, S.-K.; Lee, J.-Y.; Kim, J.-H.; Lim, D.-S. Electrochemical sensor based on Au nanoparticles decorated boron-doped diamond electrode using ferrocene-tagged aptamer for proton detection. J. Electroanal. Chem. 2012, 677-680, 139-144.

11. Hiratsuka, A.; Kojima, K.; Muguruma, H.; Lee, K.; Suzuki, H.; Karube, I. Electron transfer mediator micro-biosensor fabrication by organic plasma process. Biosens. Bioelctron. 2005, 21, 957-964.

12. Muguruma, H.; Uehara, H. Electron transfer mediated biosensor with plasma-polymerized film containing redox site. IEICE Trans. Electron. 2006, E89-C, 1781-1785.

13. Bean, L.S.; Heng, L.Y.; Yamin, B.M.; Ahmad, M. Photocurable ferrocene-containing poly(2-hydroxyethyl methacrylate) films for mediated amperometric glucose biosensor. Thin Solid Films 2005, 477, 104-110.

14. Bean, L.S.; Heng, L.Y.; Yamin, B.M.; Ahmad, M. The electrochemical behavior of ferrocene in a photocurable poly(methyl methacrylate-co-2-hydroxyethyl methacrylate) film for a glucose biosensor. Bioelectrochemisty 2005, 65, 157-162.

15. Nagel, B.; Gajovic-Eichelmann, N.; Scheller, F.W.; Katterle, M. Ionic topochemical tuned biosensor interface. Langmuir 2010, 26, 9088-9093.

16. Cosnier, S. Biosensors based on electropolymerized films: New trends. Anal. Bioanal. Chem. 2003, 377, 507-520.

17. Kashiwagi, Y.; Chiba, S.; Ikezoe, H.; Anzai, J. Polypyrrole-supported graphite felt for acetylene coupling reaction in solid phase. Synlett 2004, 14, 2513-2516.

18. Kashiwagi, Y.; Chiba, S.; Anzai, J. Amperometric determination of optically active 1-phenylethenol using chiral nitroxyl radical-modified polypyrrole films prepared by electrochemical polymerization. J. Electroanal. Chem. 2004, 566, 257-262.

19. Geetha, S.; Rao, C.R.K.; Vijayan, M.; Trivedi, D.C. Biosensing and drug delivery by polypyrrole. Anal. Chim. Acta 2006, 568, 119-125. 
20. Rozlosnik, N. New directions in medical biosensors employing poly(3,4-ethylenedioxy thiophene) derivative-based electrodes. Anal. Bioanal. Chem. 2009, 395, 637-645.

21. Singh, M.; Kathurouju, P.K.; Jampana, N. Polypyrrole based amperometric glucose biosensors. Sens. Actuators B 2009, 143, 430-443.

22. Higgins, M.J.; Molino, P.J.; Yue, Z.; Wallace, G.G. Organic conducting polymer-protein interactions. Chem. Mater. 2012, 24, 828-839.

23. Ates, M. A review study of (bio)sensor systems based on conducting polymers. Mater. Sci. Eng. C 2013, 33, 1853-1859.

24. Chen, J.; Burrell, A.K.; Collis, G.E.; Officer, D.L.; Swiegers, G.F.; Ťoo, C.O.; Wallace, G.G. Preparation, characterisation and biosensor application of conducting polymers based on ferrocene substituted thiophene and terthiophene. Electrochim. Acta 2002, 47, 2715-2724.

25. Fang, B.; Jiao, S.; Li, M.; Qu, Y.; Jiang, X. Label-free electrochemical detection of DNA using ferrocene-containing cationic polythiophene and PNA probes on nanogold modified electrodes. Biosens. Bioelectron. 2008, 23, 1175-1179.

26. Lepage, P.H.; Peytavi, R.; Bergeron, M.G.; Leclerc, M. Amplification strategy using aggregates of ferrocene-containing cationic polythiophene for sensitive and specific electrochemical detection of DNA. Anal. Chem. 2011, 83, 8086-8092.

27. Liu, A.; Anzai, J. Use of polymeric indicator for electrochemical DNA sensors: Poly(4-vinylpyridine) derivative bearing [Os(5,6-dimethyl-1,10- phenanthroline $\left.)_{2} \mathrm{Cl}\right]^{2+}$. Anal. Chem. 2004, 76, 2975-2980.

28. Şenel, M. Construction of reagentless glucose biosensor based on ferrocene conjugated polypyrrole. Synthe. Met. 2011, 161, 1861-1868.

29. Ariga, K.; Hill, J.P.; Ji, Q. Layer-by-layer assembly as a versatile bottom-up nanofabrication technique for exploratory research and realistic application. Phys. Chem. Chem. Phys. 2007, 9, 2319-2340.

30. Lutkenhaus, J.L.; Hammond, P.T. Electrochemically enabled polyelectrolyte multilayer devices: From fuel cells to sensors. Soft Matter 2007, 3, 804-816.

31. Kharlampieva, E.; Kozlovskaya, V.; Sukhishvili, S.A. Layer-by-layer hydrogen-bonded polymer films: From fundamentals to applications. Adv. Mater. 2009, 21, 3053-3065.

32. Van der Gucht, J.; Spruijt, E.; Lemmers, M.; Stuart, M.A.C. Polyelectrolyte complexes: Bulk phases and colloidal systems. J. Colloid Interface Sci. 2011, 361, 407-422.

33. Takahashi, S.; Sato, K.; Anzai, J. Layer-by-layer construction of protein architectures through avidin-biotin and lectin-sugar interactions for biosensor applications. Anal. Bioanal. Chem. 2012, 402, 1749-1758.

34. Deshmukh, P.K.; Ramani, K.P.; Singh, S.S.; Tekade, A.R.; Chatap, V.K.; Patil, G.B.; Bari, S.B. Stimuli-sensitive layer-by-layer (LbL) self-assembly systems: Targeting and biosensory applications. J. Control. Release 2013, 166, 294-306.

35. Sakr, O.S.; Borchard, G. Encapsulation of enzymes in layer-by-layer (LbL) structures: Latest advances and applications. Biomacromolecules 2013, 14, 2117-2135.

36. Hoshi, T.; Akase, S.; Anzai, J. Preparation of multilayer thin films containing avidin through sugar-lectin interactions and their binding properties. Langmuir 2002, 18, 7024-7028. 
37. Sato, K.; Kodama, D.; Naka, Y.; Anzai, J. Electrochemically induced disintegration of layer-by-layer-assembled thin films composed of 2-iminobiotin-labeled poly(ethyleneimine) and avidin. Biomacromolecules 2006, 7, 3302-3305.

38. Sato, K.; Suzuki, I.; Anzai, J. Preparation of polyelectrolyte-layered assemblies containing cyclodextrin and their binding properties. Langmuir 2003, 19, 7406-7412.

39. Crouzier, T.; Boudou, T.; Picart, C. Polysaccharide-based polyelectrolyte multilayer. Curr. Opin. Colloid Interface Sci. 2010, 15, 417-426.

40. Takita, R.; Yoshida, K.; Anzai, J. Redox properties of ferricyanide ion on layer-by-layer deposited poly(glutamic acid) film-coated electrodes and its use for electrocatalytic sensing of ascorbic acid. Sens. Actuators B 2007, 121, 54-60.

41. Zhao, W.; Xu, J.-J.; Chen, H.-Y. Electrochemical biosensors based on layer-by-layer assemblies. Electroanalysis 2006, 18, 1737-1748.

42. El-Hashani, A.; Toutianoush, A.; Tieke, B. Layer-by-layer assembled membranes of protonated 18-azacrown-6 and polyvinylsulfate and their application for highly efficient anion separation. J. Phys. Chem. B 2007, 111, 8582-8588.

43. Inoue, H.; Anzai, J. Stimuli-sensitive thin films prepared by a layer-by-layer deposition of 2-iminobiotin-labeled poly(ethyleneimine) and avidin. Langmuir 2005, 21, 8354-8359.

44. Sato, K.; Takahashi, S.; Anzai, J. Layer-by-layer thin films and microcapsules for biosensors and controlled release. Anal. Sci. 2012, 28, 929-938.

45. Hodak, J.; Etchenique, R.; Calvo, E.J. Layer-by-layer self-assembly of glucose oxidase with a poly(allylamine)ferrocene redox mediator. Langmuir 1997, 13, 2708-2716.

46. Zhang, S.; Yang, W.; Niu, Y.; Sun, C. Multilayered construction of glucose oxidase and poly(allylamine)ferrocene on gold electrodes by means of layer-by-layer covalent attachment. Sens. Actuators B 2004, 101, 387-393.

47. Fushimi, T.; Oda, A.; Ohkita, H.; Ito, S. Fabrication and electrochemical properties of layer-by-layer deposited ultrathin polymer films bearing ferrocene moieties. Thin Solid Films 2005, 484, 318-323.

48. Liu, A.; Kashiwagi, Y.; Anzai, J. Polyelectrolyte multilayer films containing ferrocene: Effects of polyelectrolyte type and ferrocene contents in the film on the redox properties. Electroanalysis 2003, 15, 1139-1142.

49. Liu, A.; Anzai, J. Ferrocene-containing polyelectrolyte multilayer film-coated electrodes: Electrocatalytic determination of ascorbic acid and use of inner blocking layers to improve the upper detection limit of the electrodes. Anal. Bioanal. Chem. 2004, 380, 98-103.

50. Liu, A.; Anzai, J. Ferrocene-containing polyelectrolyte multilayer films: Effects of electrochemically inactive surface layers on the redox properties. Langmuir 2003, 19, 4043-4046.

51. Sato, H.; Anzai, J. Preparation of layer-by-layer thin films composed of DNA and ferrocene-bearing poly(amine)s and their redox properties. Biomacromolecules 2006, 7, 2072-2076.

52. Suye, S.; Matsuura, T.; Kimura, T.; Zheng, H.; Hori, T.; Amano, Y.; Katayama, H. Amperometric DNA sensor using gold electrode modified with polymerized mediator by layer-by-layer adsorption. Microelectron. Eng. 2005, 81, 441-447. 
53. Suye, S.; Zheng, H.; Okada, H.; Hori, T. Assembly of alternating polymerized mediator, polymerized coenzyme, and enzyme modified electrode by layer-by-layer adsorption technique. Sens. Actuators B 2005, 108, 671-675.

54. Zheng, H.; Hirose, Y.; Kimura, T.; Suye, S.; Hori, T.; Katayama, H.; Arai, J.; Kawakami, R.; Ohshima, T. L-proline sensor based on layer-by-layer immobilization of thermostable dye-linked L-proline dehydrogenase and polymerized mediator. Sci. Technol. Adv. Mater. 2006, 7, 243-248.

55. Zheng, H.; Zhou, J.; Okezaki, Y.; Suye, S. Construction of L-lysine sensor by layer-by-layer adsorption of L-lysine dehydrogenase and ferrocene-labeled high molecular weight coenzyme derivative on gold electrode. Electroanalysis 2008, 24, 2685-2691.

56. Liu, X.; Wang, F, Han, S.; Shi, L.; Xu, G. Self-assembly of gold nanoparticles/electroactive polyelectrolyte multilayer films for tunable electrocatalysis. Electroanalysis 2010, 22, 963-968.

57. Du, Y.; Chen, C.; Yin, J.; Li, B.; Zhou, M.; Dong, S.; Wang, E. Solid-state probe based on electrochemical aptasensor for cocaine: A potentially convenient, sensitive, repeatable, and integrated sensing platform for drugs. Anal. Chem. 2010, 82, 1556-1563.

58. Du, Y.; Chen, C.; Yin, J.; Li, B.; Zhou, M.; Wang, E.; Dong, S. Layer-by-layer electrochemical biosensor with aptamer-appended active polyelectrolyte multilayer for sensitive protein determination. Biosens. Bioelectron. 2010, 25, 1902-1907.

59. Li, Z.; Konno, T.; Takai, M.; Ishihara, K. Fabrication of polymeric electron-transfer mediator/enzyme hydrogel multilayer on an $\mathrm{Au}$ electrode in a layer-by-layer process. Biosens. Bioelectron. 2012, 34, 191-196.

60. Hempenius, M.A.; Péter, M.; Robins, N.S.; Kooij, E.S.; Vancso, G.J. Water-soluble poly(ferrocenylsilanes) for supramolecualr assemblies by layer-by-layer deposition. Langmuir 2002, 18, 7629-7634.

61. Ma, Y.; Hempenius, M.A.; Vancso, G.J. Electrostatic assembly with poly(ferrocenylsilanes). J. Inorg. Organomet. Polym. Mater. 2007, 17, 3-18.

62. Ma, Y.; Dong, W.; Hempenius, M.A.; Möhwald, H.; Vancso, G.J. Redox-controlled molecular permeability of composite-wall microcapsules. Nat. Mater. 2006, 5, 724-729.

63. Ma, Y.; Dong, W.; Kooij, E.S.; Hempenius, M.A.; Möhwald, H.; Vancso, G.J. Supramolecular assembly of water-soluble poly(ferrocenylsilanes): Multilayer structures on flat interfaces and permeability of microcapsules. Soft Matter 2007, 3, 889-895.

64. Song, J.; Janczewski, M.Y.; Hempenius, M.; Xu, J.; Vancso, G.J. Redox-controlled release of molecular payloads from multilayered organometallic polyelectrolyte films. J. Mater. Chem. B 2013, 1, 828-834.

65. Sui, X.; Feng, X.; Song, J.; Hempenius, M.A.; Vancso, G.J. Electrochemical sensing by surface-immobilized poly(ferrocenylsilane) grafts. J. Mater. Chem. 2012, 22, 11261-11267.

66. Ludden, M.J.W.; Peter, M.; Reinhoudt, D.N.; Huskens, J. Attachment of streptavidin to $\beta$-cyclodextrin molecular printboards via orthogonal host-guest and protein-ligand interactions. Small 2006, 2, 1192-1202.

67. Villalonga, R.; Cao, R.; Fragoso, A. Supramolecular chemistry of cyclodextrin in enzyme technology. Chem. Rev. 2007, 107, 3088-3116. 
68. Ortiz, M.; Torréns, M.; Alakulppi, N.; Strömbom, L.; Fragoso, A.; O’Sulivan, C.K. Amperometric supramolecular genosensor self-assembled on cyclodextrin-modified surfaces. Electrochem. Commun. 2011, 13, 578-581.

69. Fragoso, A.; Ortiz, M.; Sanroma, B.; O’Sulivan, C.K. Multilayered catalytic biosensor self-assembled on cyclodextrin-modified surfaces. J. Incl. Phenom. Macrocycl. Chem. 2011, 69, 355-360.

70. Scott, S.J.; Mortimer, R.J.; McKenzie, K.J.; Marken, F. Mesoporous $\mathrm{TiO}_{2}$ carboxymethyl- $\gamma$-cyclodextrin multi-layer host films: Effects on adsorption and electrochemistry of 1,1'-ferrocenedimethanol. Analyst 2005, 130, 358-363.

71. Ortiz, M.; Torréns, M.; Canela, N.; Fragoso, A.; O'Sulivan, C.K. Supramolecular confinement of polymeric electron transfer mediator on gold surface for picomolar detection of DNA. Soft Matter 2011, 7, 10925-10930.

72. Suzuki, I.; Egawa, Y.; Mizukawa, Y.; Hoshi, T.; Anzai, J. Construction of positively-charged layered assemblies assisted by cyclodextrin complexation. Chem. Commun. 2002, 21, 164-165.

73. Wang, Z.; Feng, Z.; Gao, C. Stepwise assembly of the same polyelectrolytes using host-guest interaction to obtain microcapsules with multiresponsive properties. Chem. Mater. 2008, 20, 4194-4199.

74. Rao, S.V.; Anderson, K.W.; Bachas, L.G. Controlled layer-by-layer immobilization of horseradish peroxidase. Biotechnol. Bioeng. 1999, 65, 389-396.

75. Inoue, H.; Sato, K.; Anzai, J. Disintegration of layer-by-layer assemblies composed of 2-iminobiotin-labeled poly(ethyleneimine) and avidin. Biomacromolecules 2005, 6, 27-29.

76. Anzai, J.; Kobayashi, Y. Construction of multilayer thin films of enzymes by means of sugar-lectin interactions. Langmuir 2000, 16, 2851-2856.

77. Sato, K.; Imoto, Y.; Sugama, J.; Seki, S.; Inoue, H.; Odagiri, T.; Hoshi, T.; Anzai, J. Sugar-induced disintegration of layer-by-layer assemblies composed of concanavalin A and glycogen. Langmuir 2005, 21, 797-799.

78. Yang, S.; Chen, Z.; Jin, X.; Lin, X. HRP biosensor based on sugar-lectin biospecific interactions for the determination of phenolic compounds. Electrochim. Acta 2006, 52, 200-205.

79. Padeste, C.; Steiger, B.; Grubelnik, A.; Tiefenauer, L. Redox labeled avidin for enzyme sensor architectures. Biosens. Bioelectron. 2003, 19, 239-247.

80. Padeste, C.; Steiger, B.; Grubelnik, A.; Tiefenauer, L. Molecular assembly of redox-conductive ferrocene-streptavidin conjugates-Towards bio-electrochemical devices. Biosens. Bioelectron. 2004, 20, 545-552.

81. Kwaon, S.J.; Park, N.; Kwon, D.; Kwak, J. Electrochemical detection of biomolecule with mixed self-assembled monolayer of ferrocene-undecanethiol. J. Nanosci. Nanotechnol. 2011, 11, 4194-4199.

82. Casas-Solvas, J.M.; Ortiz-Salmerón, E.; García-Fuentes, L.; Vargas-Berenguel, A. Ferrocene-mannose conjugates as electrochemical molecular sensors for concanavalin A lectin. Org. Biomol. Chem. 2008, 6, 4230-4235.

83. Martos-Maldonado, M.C.; Casas-Solvas, J.M.; Quesada-Soriano, I.; García-Fuentes, L.; Vargas-Berenguel, A. Poly(amido amine)-based mannose-glycodendrimers as multielectron redox probes for improving lectin sensing. Langmuir 2013, 29, 1318-1326. 
84. Martos-Maldonado, M.C.; Thygesen, M.B.; Jensen, K.J.; Vargas-Berenguel, A. Gold-ferrocene glycol-nanoparticles for high-sensitivity electrochemical detection of carbohydrate-lectin interactions. Eur. J. Org. Chem. 2013, 2793-2801.

85. Sato, K.; Kodama, D.; Anzai, J. Electrochemical determination of sugars by use of multilayer thin films of ferrocene-appended glycogen and concanavalin A. Anal. Bioanal. Chem. 2006, 386, 1899-1904.

86. Wang, X.; Dong, P.; He, P.; Fang, Y. A solid-state electrochemiluminescence sensing platform for detection of adenosine based on ferrocene-labeled structure-switching signaling aptamer. Anal. Chim. Acta 2010, 658, 128-132.

87. Liu, X.; Li, Y.; Zheng, J.; Zhang, J.; Sheng, Q. Carbon nanotube-enhanced electrochemical aptasensor for the detection of thrombin. Talanta 2010, 81, 1619-1624.

88. Qiu, S.; Gao, S.; Xie, L.; Chen, H.; Liu, Q.; Lin, Z.; Qiu, B.; Chen, G. An ultra-sensitive electrochemical sensor for ascorbic acid based on click chemistry. Analyst 2011, 136, 3962-3966.

89. Li, Y.; Cai, C. Click chemistry-based functionalization on non-oxidized silicon substrates. Chem. Asian J. 2011, 6, 2592-2605.

90. Li, D.; Gill, R.; Freeman, R.; Willner, I. Probing of enzyme reactions by the biocatalyst-induced association or dissociation of redox labels liked to monolayer-functionalized electrodes. Chem. Commun. 2006, 5027-5029.

91. Halámek, J.; Wollenberger, U.; Stöcklein, W.; Scheller, F.W. Development od a biosensor for glycated hemoglobin. Electrochim. Acta 2007, 53, 1127-1133.

92. Chien, H.-C.; Chou, T.-C. A nonenzymatic amperometric method for fructosy-valin sensing using ferroceneboronic acid. Electroanalysis 2011, 23, 402-408.

93. Takahashi, S.; Abiko, N.; Haraguchi, N.; Fujita, H.; Seki, E.; Ono, T.; Yoshida, K.; Anzai, J. Voltammetric response of ferroceneboronic acid to diol and phenolic compounds as possible pollutants. J. Environ. Sci. 2011, 23, 1027-1032.

94. Takahashi, S.; Haraguchi, N.; Abiko, N.; Ono, T.; Yoshida, K.; Anzai, J. Voltammetric determination of salicylic acid and derivatives based on ferroceneboronic acid. Sens. Lett. 2011, 9, 1845-1848.

95. Egawa, Y.; Seki, T.; Takahashi, S.; Anzai, J. Electrochemical and optical sugar sensors based on phenylboronic acid and its derivatives. Mater. Sci. Eng. C 2011, 31, 1257-1264.

96. Wang, Z.; Etienne, M.; Quilès, F.; Kohring, G.W.; Walcarius, A. Durable cofactor immobilization in sol-gel bio-composite thin films for reagentless biosensors and bioreactors using dehydrogenases. Biosens. Bioelectron. 2012, 32, 111-117.

97. Merchant, S.A.; Tran, T.O.; Meredith, M.T.; Cline, T.C.; Glatzhofer, D.T.; Schmidtke, D.W. High-sensitive amperometric biosensors based on ferrocene-modified linear poly(ethyleneimine). Langmuir 2009, 25, 7736-7742.

98. Meredith, M.T.; Hickey, D.P.; Redemann, J.P.; Schmidtke, D.W.; Glatzhofer, D.T. Effects of ferrocene methylation on ferrocene-modified linear poly(ethyleneimine) bioanodes. Electrochim. Acta 2013, 92, 226-235. 
99. Nagarale, R.K.; Lee, J.M.; Shin, W. Electrochemical properties of ferrocene modified polysiloxane/chitosan nanocomposite and its application to glucose sensor. Electrochim. Acta 2009, 54, 6508-6514.

100. Frasconi, M.; Deriu, D.; D'Annibale, A.; Mazzei, F. Nanostructured materials based on the integration of ferrocenyl-tethered dendrimer and redox proteins on self-assembled monolayers: An efficient biosensor interface. Nanotechnology 2009, 20, doi:10.1088/0957-4484/20/50/505501.

101. Mintzer, M.A.; Grinstaff, M.W. Biomedical applications of dendrimers: A tutorial. Chem. Soc. Rev. 2011, 40, 173-190.

102. Sato, K.; Anzai, J. Dendrimers in layer-by-layer assemblies: Synthesis and applications. Molecules 2013, 18, 8440-8460.

103. Merechant, S.A.; Glatzhofer, D.T.; Schmidtke, D.W. Effects of electrolyte and pH on the behavior of cross-liked films of ferrocene-modified poly(ethyleneimine). Langmuir 2007, 23, 11295-11302.

104. Bunte, C.; Rühe, J. Photochemical generation of ferrocene-based redox-polymer networks. Macromol. Rapid Commun. 2009, 30, 1817-1822.

105. Guo, S.; Wang, E. Synthesis and electrochemical applications of gold nanoparticles. Anal. Chim. Acta 2007, 598, 181-192.

106. Prakash, S.; Chakrabarty, T.; Singh, A.K.; Shahi, V.K. Polymer thin films embedded with metal nanoparticles for electrochemical biosensors applications. Biosens. Bioelectron. 2013, 41, 43-53.

107. Siangproh, W.; Dungchai, W.; Rattanarat, P.; Chailapakul, O. Nanoparticle-based electrochemical detection in conventional and miniaturized systems and their bioanalytical applications: A review. Anal. Chim. Acta 2011, 690, 10-25.

108. Fang, Y.; Zhang, D.; Qin, X.; Miao, Z.; Takahashi, S.; Anzai, J.; Chen, Q. A non-enzymatic hydrogen peroxide sensor based on poly(vinyl alcohol)-multiwalled carbon nanotubes-platinum nanoparticles hybrids modified glassy carbon electrode. Electrochim. Acta 2012, 70, 266-271.

109. Arya, S.K.; Saha, S.; Ramirez-Vick, J.E.; Gupta, V.; Bhansali, S.; Singhg, S.P. Recent advances in $\mathrm{ZnO}$ nanoparticles and thin films for biosensor applications: Review. Anal. Chim. Acta 2012, $737,1-21$.

110. Shi, H.; Yang, Y.; Huang, J.; Zhao, Z.; Xu, X.; Anzai, J.; Osa, T.; Chen, Q. Amperometric choline biosensors prepared by layer-by-layer deposition of choline oxidase on the Prussian blue-modified platinum electrode. Talanta 2006, 70, 852-858.

111. Shukla, S.K.; Mishra, A.K.; Arotiba, O.A.; Mamba, B.B. Chitosan-based nanomaterials: A state-of-the-art review. Int. J. Biol. Macromol. 2013, 59, 46-58.

112. Takahashi, S.; Anzai, J. Phenylboronic acid monolayer-modified electrodes sensitive to sugars. Langmuir 2005, 21, 5102-5107.

113. Miao, Y.; Chen, J.; Wu, X.; Fang, K.; Jia, A.; Liu, J. Immobilization of Prussian blue nanoparticles onto thiol SAM modified $\mathrm{Au}$ electrodes for electroanalytical or biosensor applications. J. Nanosci. Nanotechnol. 2007, 7, 2877-2882.

114. Wang, J.; Li, J.; Baca, A.J.; Hu, J.; Zhou, F.; Yan, W.; Pang, D.-W. Amplified voltammetric determination of DNA hybridization via oxidation of ferrocene caps on gold nanoparticle/streptavidin conjugates. Anal. Chem. 2003, 75, 3941-3945. 
115. Baca, A.J.; Zhou, F.; Wang, J.; Hu, J.; Li, J.; Wang, J.; Chikneyan, Z.S. Attachment of ferrocene-capped gold nanoparticle/streptavidin conjugates onto electrode surfaces covered with biotinylated biomolecules for enhanced voltammetric analysis. Electroanalysis 2004, 16, 73-80.

116. Jimenez, O.A.; Chikneyan, S.; Baca, A.J.; Wang, J.; Zhou, F. Sensitive detection of sulfhydryl groups in surface-confined metallothioneins and related species via ferrocene-capped gold nanoparticle/streptavidin conjugates. Environ. Sci. Technol. 2005, 39, 1209-1213.

117. Wang, J.; Zhu, X.; Tu, Q.; Guo, Q.; Zarui, C.S.; Momand, J.; Sun, X.Z.; Zhou, F. Capture of p53 by electrodes modified with consensus DNA duplexes and amplified voltammetric detection using ferrocene-capped gold nanoparticle/streptavidin conjugates. Anal. Chem. 2008, 80, 769-774.

118. Kiu, L.; Du, J.; Li, S.; Yuan, B.; Han, H.; Jing, M.; Xia, N. Amplified voltammetric detection of dopamine using ferrocene-capped gold nanoparticle/streptavidin conjugates. Biosens. Bioelectron. 2013, 41, 730-735.

119. Jin, Y.; Lu, W.; Hu, J.; Yao, X.; Li, J. Site-specific DNA cleavage of EcoR1 endonuclease probed by electrochemical analysis using ferrocene capped gold nanoparticles as reporter. Electrochem. Commun. 2007, 9, 1086-1090.

120. Chen, M.; Diao, G. Electrochemical study of mono-6-thio-b-cyclodextron/ferrocene capped on gold nanoparticles: Characterization and application to the design of glucose amperometric biosensor. Talanta 2009, 80, 815-820.

121. Shi, H.; Xu, Y.; Wang, Y.; Song, W. Assembly of ferrocenylhexanethiol functionalized gold nanoparticles for ascorbic acid determination. Microchim. Acta 2010, 171, 81-89.

122. Escorcia, A.; Dhirani, A. Electrochemical properties of ferrocenylalkane dithiol-gold nanoparticle films prepared by layer-by-layer self-assembly. J. Electroanal. Chem. 2007, 601, 260-268.

123. Song, Z.; Yuan, R.; Chai, Y.; Zhou, Y.; Jiang, W.; Su, H.; Che, X.; Li, J. Horseradish peroxidase-functionalized $\mathrm{Pt}$ hollow nanospheres and multiple redox probes as trace labels for a sensitive simultaneous multianalyte electrochemical immunoassay. Chem. Commun. 2010, 46, 6750-6752.

124. Cai, W.; Xu, Q.; Zhao, X.; Zhu, J.; Chen, H. Porous gold-nanoparticle- $\mathrm{CaCO}_{3}$ hybrid material: Preparation, characterization, and application for horseradish peroxidase assembly and direct electrochemistry. Chem. Mater. 2006, 18, 279-284.

125. Kirdeciler, S.K.; Soy, E.; Öztürk, S.; Kucherenko, I.; Soldatkin, O.; Dzyadevych, S.; Akata, B. A novel urea conductometric biosensor based on zeolite immobilized urease. Talanta 2011, 85, 1435-1441.

126. Tian, S.; Zhou, Q.; Gu, Z.; Gu, X.; Zhao, L.; Li, Y.; Zheng, J. Hydrogen peroxide biosensor based on microperosidase-11 immobilized in a silica cavity array electrode. Talanta 2013, 107, 324-331.

127. Sun, W.; Sun, Z.; Zhang, L.; Qi, X.; Li, G.; Wu, J.; Wang, M. Application of $\mathrm{Fe}_{3} \mathrm{O}_{4}$ mesoporous sphere modified carbon ionic liquid electrode as electrochemical hemoglobin biosensor. Colloid. Surf. B 2013, 101, 177-182. 
128. Li, T.; Yang, M. Electrochemical sensor utilizing ferrocene loaded porous polyelectrolyte nanoparticles as label for the detection of protein biomarker IL-6. Sens. Actuators B 2011, 158, 361-365.

129. Dong, J.; Zhou, X.; Zhao, H.; Xu, J.; Sun, Y. Reagentless amperometric glucose biosensor based on the immobilization of glucose oxidase on a ferrocene@ NaY zeolite composite. Microchim. Acta 2011, 174, 281-288.

130. Zhang, F.; Wan, Q.; Wang, X.; Sun, Z.; Zhu, Z.; Xian, Y.; Jin, L.; Yamamoto, K. Amperometric sensor based on ferrocene-doped silica nanoparticles as an electron transfer mediator for the determination of glucose in rat brain coupled to in vivo microdialysis. J. Electroanal. Chem. 2004, 571, 133-138.

131. Li, H.; Wei, Q.; He, J.; Li, T.; Zhao, Y.; Cai, Y.; Du, B.; Qian, Z.; Yang, M. Electrochemical immunosensors for cancer biomarker with signal amplification based on ferrocene functionalized iron oxide nanoparticles. Biosens. Bioelectron. 2011, 26, 3590-3595.

132. Shang, K.; Wang, X.; Sun, B.; Cheng, Z.; Ai, S. $\beta$-cyclodextrin-ferrocene host-guest complex multifunctional labeling triple amplification strategy for electrochemical immunoassay of subgroup J of avian leukosis viruses. Biosens. Bioelectron. 2013, 45, 40-45.

133. Wang, B.; Xu, C.; Xie, J.; Yang, Z.; Sun, S. pH controlled release of chromone from chromone- $\mathrm{Fe}_{3} \mathrm{O}_{4}$ nanoparticles. J. Am. Chem. Soc. 2008, 130, 14436-14437.

134. Mahmoud, K.A.; Hrapovic, S.; Luong, J.H.T. Picomolar detection of protease using peptide/single walled carbon nanotube/gold nanoparticle-modified electrode. ACS Nano 2008, 2, 1051-1057.

135. Mahmoud, K.A.; Luong, J.H.T. Impedance method for detecting HIV-1 protease and screening for its inhibitors using ferrocene-peptide conjugate/Au nanoparticle/single-walled carbon nanotube modified electrode. Anal. Chem. 2008, 80, 7056-7062.

136. Zhou, Y.; Chai, Y.; Yuan, R.; Mao, L.; Yuan, Y.; Han, J. Glucose oxidase and ferrocene labels immobilized at $\mathrm{Au} / \mathrm{TiO}_{2}$ nanocomposites with high load amount and activity for sensitive immunoelectrochemical measurement of proGRP biomarker. Biosens. Bioelectron. 2011, 26, 3838-3844.

137. Huang, J.D.; Yang, Y.; Shi, H.B.; Song, Z.; Zhao, Z.X.; Anzai, J.; Osa, T.; Chen, Q. Multi-walled carbon nanotubes-based glucose biosensor prepared by a layer-by-layer technique. Mater. Sci. Eng. C 2006, 26, 113-117.

138. Huang, J.D.; Song, Z.; Li, J.; Yang, Y.; Shi, H.B.; Wu, B.; Anzai, J.; Osa, T.; Chen, Q. A highly-sensitive L-lactate biosensor based on sol-gel film combined with multi-walled carbon nanotubes (MWCNTs) modified electrode. Mater. Sci. Eng. C 2007, 27, 29-34.

139. Pereira, A.C.; Kisner, A.; Duran, N.; Kubota, L.T. The effects of dimensionality on electrochemical sensors based on carbon nanotubes and metallic nanowires. J. Nanosci. Nanotechnol. 2010, 10, $651-667$.

140. Zhu, Z.; Garcia-Gancedo, L.; Flewitt, A.J.; Xie, H.; Moussy, F.; Milne, W.I. A critical review of glucose biosensors based on carbon nanomaterials: Carbon nanotubes and graphene. Sensors 2012, 12, 5996-6022.

141. Yang, X.; Feng, B.; He, X.; Li, F.; Ding, Y.; Fei, J. Carbon nanomaterial based electrochemical sensors for biogenic amines. Microchim. Acta 2013, 180, 935-956. 
142. Goff, A.L.; Moggia, F.; Debou, N.; Jegou, P.; Artero, V.; Fontecave, M.; Jousselme, B.; Palacin, S. Facile and tunable functionalization of carbon nanotube electrodes with ferrocene by covalent coupling and p-stacking interactions and their relevance to glucose bio-sensing. J. Electroanal. Chem. 2010, 641, 57-63.

143. Moore, K.E.; Flavel, B.S.; Yu, J.; Abell, A.D.; Shapter, J.G. Increased redox-active peptide loading on carbon nanotube electrodes. Electrochim. Acta 2013, 89, 206-211.

144. Qiu, J.; Zhou, W.; Guo, J.; Wang, R.; Liang, R. Amperometric sensor based on ferrocene-modified multiwalled carbon nanotube nanocomposites as electron mediator for the determination of glucose. Anal. Biochem. 2009, 385, 264-269.

145. Coates, M.; Griveau, S.; Bedioui, F.; Nyokong, T. Layer-by-layer electrode functionalization using carbon nanotubes, electrochemical grafting of azide-alkyne functions and click chemistry. Electroanalysis 2012, 24, 1833-1838.

146. Qin, Y.; Liu, J.; Li, D.; Xu, L.; Liu, Y.; Wang, E. Biocompatible conductive architecture with surface-confined probe for non-invasive electrochemical cytosensing. Electrochem. Commun. 2012, 18, 81-84.

147. Liu, J.; Qin, Y.; Li, D.; Wang, T.; Liu, Y.; Wang, J.; Wang, E. Highly sensitive and selective detection of cancer cell with a label-free electrochemical cytosensor. Biosens. Bioelectron. 2013, $41,436-441$.

148. Huang, K.; Miao, Y.; Wang, L.; Gan, T.; Yu, M.; Wang, L. Direct electrochemistry of hemoglobin based on chitosan-ionic liquid-ferrocene/graphene composite film. Process Biochem. 2012, 47, 1171-1177.

149. Fan, L.; Zhang, Q.; Wang, K.; Li, F.; Niu, L. Ferrocene functionalized grapheme: Preparation, characterization and efficient electron transfer toward sensors of $\mathrm{H}_{2} \mathrm{O}_{2}$. J. Mater. Chem. 2012, 22, 6165-6170.

150. Song, Y.; Kang, X.; Zuckermann, N.B.; Phebus, B.; Konopelski, J.P.; Chen, S. Ferrocene-functionalized carbon nanoparticles. Nanoscale 2013, 3, 1984-1989.

151. Wang, J.; Chen, L.; Ho, K. Synthesis of redox polymer nanobeads and nanocomposites for glucose biosensors. ACS Appl. Mater. Interfaces 2013, 5, 7852-7861.

(C) 2013 by the authors; licensee MDPI, Basel, Switzerland. This article is an open access article distributed under the terms and conditions of the Creative Commons Attribution license (http://creativecommons.org/licenses/by/3.0/). 